\title{
Hazardous Drug Handling Awareness Among Faculty Members
}

\author{
Noor Kamil \\ Department of Pharmaceutical Sciences, College of Clinical Pharmacy, King Faisal University, Post Box 400, Al-Ahsa-31982. KINGDOM OF SAUDI ARABIA.
}

\begin{abstract}
Background: Hazard to the health care professionals from hazardous drugs and chemicals rooted out from intrinsic toxicity and the level of exposure to these drugs in the course of their job responsibilities. Any drug or chemical, which can cause genotoxicity, carcinogenicity, teratogenicity or fertility impairment and significant organ or other toxicities, will be consider as occupational hazard. Plenty of scientific reports proved the involvement of hazardous drug to the adverse health outcomes of the workers due to the absorption of these drugs while performing their duties. Similarly, the scientist dealing with numerous hazardous chemicals and drugs in health care industry are at higher risk of exposure. Material and Method: In order to determine the level of awareness of safe handling of hazardous drugs and chemicals among faculty members, a survey was conducted with a written consent in college of clinical pharmacy involved in basic health care research. Results: Survey results determined that, more than 70 percent of faculty members were aware of hazardous drugs or chemicals and know how to handle these chemicals. More than 80 percent were unaware of any hazardous drug program or proper engineering control, there were less than 35 percent of members know how to deal with accidental spill or
\end{abstract}

exposure of such drugs, whereas more than half of the faculty members population was unaware of the most common route of exposure of hazardous drugs. Conclusion: Hence, it is necessary to design a hazardous drug program and proper engineering control to train and educate researchers to prevent and control expected exposures of hazardous drugs according to the $\mathrm{NIOSH}$ recommendations.

Key words: Biohazard, Biosafety Engineering Control, Health Hazard, Hazardous drugs, Cytotoxic, Safe handling guidelines, Work protection.

Correspondence :

Noor Kamil,

Department of Pharmaceutical Sciences, College of Clinical Pharmacy, King Faisal University, Post Box 400, Al-Ahsa-31982. KINGDOM OF SAUDI ARABIA. Tel: +966135895448

E-mail: drnoorkamil@gmail.com

DOI: 10.5530/jyp.2016.4.28

\section{INTRODUCTION}

If drugs shown some health problems in humans and animals with a potential to cause either acute or chronic adverse effects like dermal rashes, reproductive problems such as infertility, fetal abnormalities and abortions and possibly can cause various cancers like leukemia at low doses would be labeled as hazardous. ${ }^{1-3}$ Similarly work-related exposures to these hazardous chemicals can appeared as acute toxicities on skin like contact dermatitis ${ }^{4,5}$ and chronic toxicities such as adverse reproductive effects ${ }^{6-8}$ and various cancers. ${ }^{9}$ Approximately eight million of health care workers are exposed to hazardous drugs in USA, which include pharmacy and nursing staff, physicians, operation theater staff, environmental services worker force, and personnel working in research labs, veterinary facilities, and peoples working in shipping and receiving chemicals and drugs. ${ }^{10}$ Personnel exposed themselves intentionally or unintentionally to these hazardous chemicals or drugs in various ways; for example by aerosolized the chemicals, making dust, cleaning the spills, or exposed to contaminated work surface or equipment either in health care facilities or research laboratories involved in extemporaneous compounding, mixing, administering or disposing of patients waste and hazardous chemicals and drugs. ${ }^{1}$ Pharmacists and nurses exposed to hazardous drugs reported increase in adverse reproductive incidents including, stillbirths, inborn errors, fetal abnormalities, spontaneous abortions when compared to unexposed personnel..$^{1,2}$

There are a number of factors, which can affect worker exposures. For example, drug handling techniques (including preparation, administration and disposal methods), quantity, frequency and duration of drug handled, personnel's potential route of exposure, use of safety cabinets, PPE (personal protective equipment) and standard operating procedures. ${ }^{11}$ Lack of proper standards operating procedure will increase the likelihood of workers to adverse effects of such drugs as the amount and frequency of these hazardous drugs is increased. Biological markers were used in studies to assess the level of exposures, but there is no single marker is discovered to indicate the hazardous drug exposure or predict the injurious health effects. ${ }^{12}$ Sessink and Bos $^{13}$ noted that in 11 of 12 reports, cyclophosphamide was detected in the urine of health care workers despite the safety measures. Health care workers who did not handle hazardous drugs directly but exposed through escaped aerosols or contaminated work surfaces, clothing or drug containers were found to have hazardous drugs in their urine..$^{14} \mathrm{~A}$ quantifiable amount of some hazardous drugs were also documented the urine of health care workers who either prepared or administered the drugs no matter how many safety precautions were in place. ${ }^{15,16}$ American Society of Hospital Pharmacists (ASHP) first used the term hazardous drug and OSHA (Occupational Safety and Health Administration) is still using this term in its literature. ${ }^{17,18}$ Previously it was though that, only anticancer drugs are involved in occupational exposure to hazardous drugs.

Earlier only cancer therapy drugs were considered as hazardous agents; therefore, terms like "antineoplastics and chemotherapy" were mentioned in previous literature and guidelines. It is now established that, neither all the antineoplastics are cytotoxic nor all the cytotoxic drugs are exclusively use in cancer treatment. The term "cytotoxic" is used to denote any agent that is oncogenic, genotoxic, mutagenic, teratogenic or cause any potential hazard. ${ }^{19}$ Due to the continuous development and understanding of many such agents and new hazardous drugs (biotech drugs and genotoxic biologicals), the term "cytotoxic" becomes less appropriate. ${ }^{20}$ It is imperative for health care industry, whose slogan is to take care the sick and suffering, to make their employees safe from hazards, instead of making itself a high-risk area. The magnitude of health hazard is based on the worker's extent of exposure and type of toxic agent. Workers can be best protected via proper engineering and administrative controls and suitable personal protective equipment from exposure of various hazardous drugs and chemicals. A worker is exposed to these hazardous agents throughout his life right from the synthesis to shipment and distribution, to use in any health care facility, until the disposal of waste. ${ }^{21}$ Although a number of guidelines have been issued form various agencies, but 
reports showed a poor compliance. ${ }^{22,23}$ Environmental studies of facilities involved in patient-care, which seems to follow the recommended guidelines for handling the hazardous drugs are also documented measurable amount of drug contamination..$^{14,15,24}$ In 1980s and 1990s after the revelations of many published articles extra precautionary measures like additional methods to monitor and document the exposures were recommended in various papers to protect workers. ${ }^{25}$

In addition, strict administrative programs for control and training, proper and more secure engineering controls, and use of effective personal protective equipment (PPE) were also proposed. ${ }^{17,19}$ In order to reinforce the level of awareness and provide necessary measures for protection of health care workers and their employers about the risks involved in exposure of hazardous drugs. In September 2004, CDC (centers for the disease control and prevention) department of health and human services, NIOSH (national institute of occupational safety and health) issued "NIOSH Alert: Preventing Occupational Exposures to Antineoplastic and Other Hazardous Drugs in Health Care Settings". The area of hazardous drug exposure of workers was not rich in research projects and publications since NIOSH Alert published in 2004, after wards it was the area filled with published guidelines and publications of measurements of hazardous drugs exposure in the workplace and studies of workers exposures and their overall health effects. Later on, publications proved incidences of exposure were decreased but continually occurring. ${ }^{26,27}$ Monitoring methods and techniques to detect most of the drugs used in health care settings are still not developed. Although NIOSH Alert offered plenty of useful choices for workers and workplace safety evaluations, safety assurance; like, effective hazardous drug programs, maximum utilization of engineering controls, extensive workers training programs, greater use of personal protective equipment to minimize occupational exposures but still few institutions are complying fully. ${ }^{10}$

A questionnaire-based survey has been designed to determine the level of safety awareness among faculty members and researchers to hazardous drugs practice standards described in NIOSH alert. Survey comprised of many important questions mentioned in Table 1.

\section{METHODS}

A simple questioner based survey entitled "Survey of biohazard safety awareness" was conducted among 39 different faculty members and clinical preceptors of College of Clinical Pharmacy of King Faisal University, Al-Ahsa, KSA which were involved in teaching, research and training of undergraduate pharmacy students in various hospitals in the city.

Survey questions are mentioned in the Table 1. For most answers, the participants were simply asked to circle the responses that applied to them or check YES or NO.

Survey was followed by a detailed lecture presentation to provide the detailed recommendations for the safe handling of hazardous drugs. All the important aspects of the prevention of hazardous drug exposures were covered in the presentation. It included significance of the issue with previous published reports, routes of expose, recommendation of some important authorities like OSHA, NIOSH and SHPA (Society of Hospital Pharmacist of Australia) to describe PPE, ventilation control, hazardous waste containment and disposal.

\section{RESULTS}

Nearly all the complete responses were returned, or about a $95 \%$ response rate. Some basic demographic data about the faculty members' population from which the sample was drawn were available, so the degree of representativeness of the sample of responders could be determined. The survey results provide useful descriptive information about the responding faculty' knowledge and practices in handling hazardous drugs at all levels. Survey begins with a couple of very basic information of hazardous drugs handling, i.e., awareness of typical identification mark or symbol on hazardous drugs labels or preparation/storage facility, 57 percent responded 'yes' while 43 percent responded 'no' to first question (Table 1). While 72 percent responded 'yes' to the specific symbol (Figure 1) used in cytotoxic drugs prepared in a proper facility and 28 percent marked 'yes' for all the anticancer drugs irrespective of their cytotoxicity in question number 2. Rest of the all other questions were related to the level of awareness for the hazardous drug information, hazardous drug program, routes of accidental exposure, proper engineering controls and ability to deal with accidental exposure of such drugs. About 71 percent were aware of any hazardous chemical or drug they are using, whereas 29 percent were unaware. Seventy-five percent individuals declared that they were aware of how to handle the hazardous drugs and chemicals but rest of 25 percent were unaware.

Even though one of the major recommendations of the NIOSH Alert was the implementation and annual review of programs for safely handling hazardous drugs and associated training, only $18 \%$ of researchers surveyed were aware of such programs. Hazardous drug exposure assessment was a key recommendation in the 2004 NIOSH Alert. It recommended acomprehensive workplace evaluation of equipment, layout, drugs, volumes, frequency, decontamination, waste handling, and the equipment used to control exposures.

A variety of engineering controls for the safe use and handling of hazardous drugs have been recommended by the NIOSH Alert and numerous other publications. These include the use of such devices as closed and exhausted mixing systems, laminar flow benches, bench top ductless hoods, general room ventilation, and local exhaust ventilation systems. Fewer than $15 \%$ responders were aware of engineering control method in place at research laboratories for control of hazardous drug exposure. Most of the responses indicated their awareness of general ventilation or filtration systems and the use of closed containers.

In response to one of the most important question, "how to deal with the accidental exposure of hazardous drugs or chemical" only 35 percent participants said they were aware of the technique to deal with the accidental exposure of hazardous drugs. It is interesting and important to note here that other administrative controls to minimize exposures to the public from hazardous drugs were not implemented thoroughly.

Exposure to hazardous drugs may occur through skin contact, inhalation, ingestion, or injection. Skin contact and inhalation are the most likely ways a worker may be exposed to hazardous drugs. However, ingestion (from hand to mouth) or injection through a needle stick or sharps injury is also possible. Knowledge of researchers towards the most common routes of accidental exposure was not satisfactory; fewer than 45 percent marked 'yes' to that question.

\section{DISCUSSION}

Keeping in mind the fact that, the response rates of very lengthy surveys are very low; a very simplified but comprehensive (enough to provide basic information) survey has been designed to chalk out the level of awareness among very experienced and educated faculty members involved in multiple research projects. I believed that the survey results represented the deficient areas in implementing the NIOSH guidelines for safe handling of biohazard drugs and chemicals. Despite the NIOSH Alert and other papers that have more recently indicated the likelihood of continued occupational exposures to hazardous drugs in health care professionals, there were indications that at least studied teaching institute in this study has not fully implemented the recommendations.

Awareness begins with the identification of the hazardous drugs or chemicals. Various warning signs are used to describe the type of toxicity 


\section{Table 1: Survey Questions for biohazard safety awareness}

Survey for Awareness of biohazard drugs and chemicals
Are these symbols familiar to you?
Where this symbol is used (drugs prepared in a proper facility)?
Do you know any hazardous drug/s, which you are using?
Do you know how to handle the hazardous drugs/chemicals?
Are you aware of any hazardous drug program?
Do you know the most common route of accidental exposures of hazardous drugs?
Do you know the proper engineering controls such as ventilation and special drug handling equipment?
Do you know how to deal with accidental exposure of any hazardous drugs or chemicals?

A total 8 questions were mentioned in survey excluding the other demographic information of responders like name, designation, research experience etc.

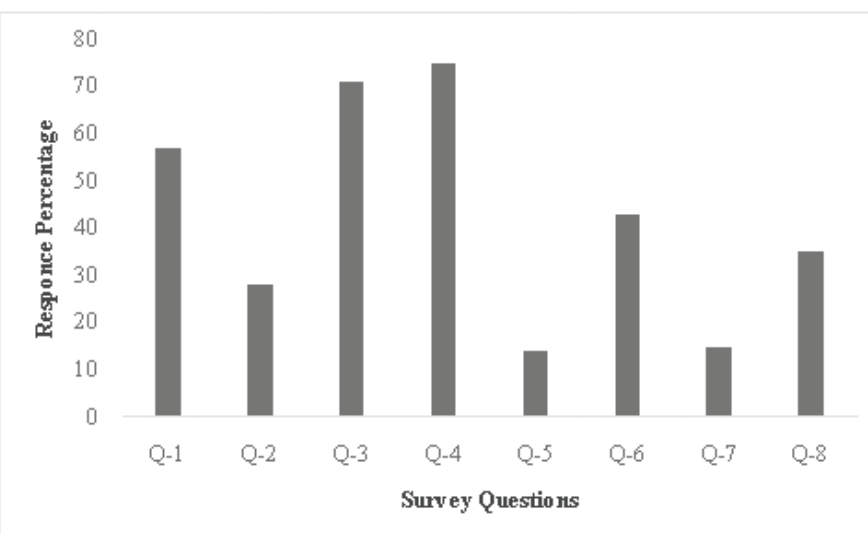

Figure 1: Percentile responses of survey questions.

Responses of various questions are expressed in percentages "Yes" Survey Questions are mentioned in Table 1.

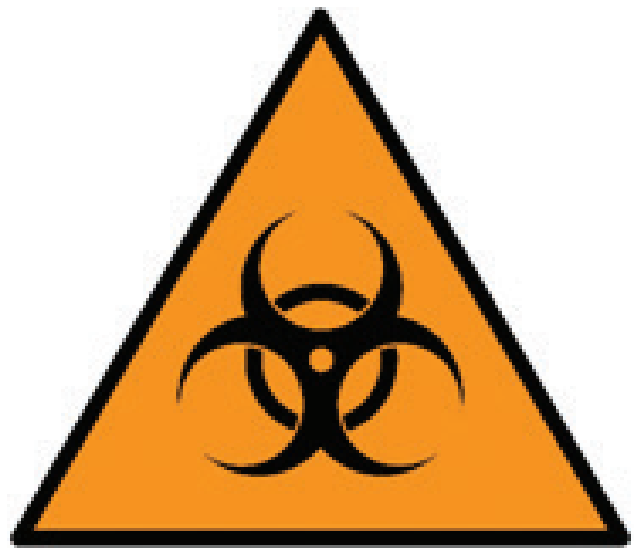

Figure 2: Typical Biohazard Symbol.

Charles Baldwin's original most frequently used biohazard symbol for labeling of hazardous biological materials including viral samples and used syringe needles.

or hazard e.g., general caution sign, toxic sign, ionization radiation sign, non-ionizing radiation sign, biohazard sign to label the biohazard chemicals and facilities to handle these drugs. The basic design for the international symbol for biological hazard (Figure 2) remained the same with minor

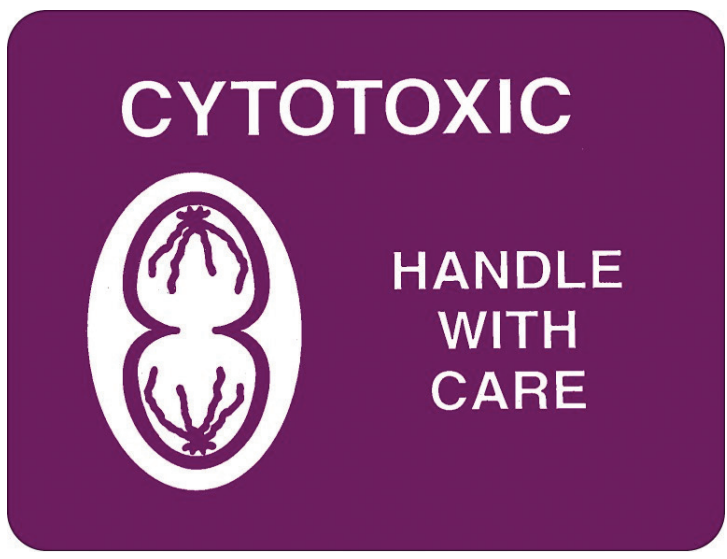

Figure 3: Cytotoxic hazard symbol.

SHPA purple symbol representing a cell in late telophase used to identify cytotoxic materials.

innovations. Whereas another symbol is used for, cytotoxic drugs in some countries showing the cell division in late telophase (Figure 3). The symbol for biohazard developed in 1966 by Charles Baldwin, an environmental-health engineer working for the Dow Chemical Company on the containment products in designing containment systems for the Cancer Institute at the National Institutes of Health. ${ }^{28}$ It is used to label the hazardous biological materials considering a significant health risk, including viral samples and used hypodermic needles. Although more than 70 percent of researchers claimed that, they were aware of the hazardous drugs and chemicals and their proper handling techniques but their awareness of engineering control and dealing of accidental exposure was very poor. The lack of worker awareness about written programs or policies, absence of training, and the lack of appropriate controls or protective equipment demonstrate that there is still much work to do to evaluate worker exposures to hazardous drugs and to identify appropriate controls. In addition to the results of the survey study, it has been the experience of the author through interaction with numerous researchers and laboratory technicians that there is still considerable misunderstanding of the definition of a "hazardous" drug. Typically, researchers quickly identify chemotherapeutic agents as hazardous, but they seldom consider such drugs from the NIOSH list-as estrogen, ganciclovir, or fluoxymesterone as hazardous. Cancer-fighting drugs are not the only ones in the health care workplace that can cause harm to workers if they are exposed, but due to the assumption that only chemotherapy agents 
are harmful, there is less concern for control and worker protection in other areas outside those departments.

There are hundreds of new drugs and drug applications developed and approved each year. The NIOSH list updated in 2012 and should not be considered "all inclusive" at this time. The potential exposures and appropriate controls for each new drug and new application should be evaluated by an industrial hygienist who works closely with medical, nursing, and pharmaceutical staff. Employers are ultimately responsible for identifying the hazards of agents that workers are exposed to and for implementing engineering, administrative, and personal protective equipment controls for ensuring the safety of the staff and the public.

It is evident form the survey that, the knowledge of participants regarding the most common route of accidental exposure is not satisfactory. Exposures to hazardous drugs may occur through inhalation, skin contact, skin absorption, ingestion, or injection. Inhalation and skin contact/absorption are the most likely routes of exposure, but unintentional ingestion from hand to mouth contact and unintentional injection through a needle-stick or sharps injury are also possible. ${ }^{29,30}$ A number of studies have attempted to measure airborne concentrations of antineoplastic drugs in health care settings. ${ }^{31-33}$ In most cases, the percentage of air samples containing measurable airborne concentrations of hazardous drugs was low, and the actual concentrations of the drugs, when present, were quite low. These results may be attributed to the inefficiency of sampling and analytical techniques used in the past. ${ }^{33}$ Both particulate and gaseous phases of one antineoplastic drug, cyclophosphamide, have been reported in two studies. ${ }^{32,33}$ Since the early 1990s, various studies have examined environmental contamination of areas where hazardous drugs are prepared and administered at health care facilities in the United States and several other countries. ${ }^{34-38}$ Using wipe samples, most investigators measured detectable concentrations of one to five hazardous drugs in various locations such as biological safety cabinet (BSC) surfaces, floors, counter tops, storage areas, tables and chairs in patient treatment areas, and locations adjacent to drug-handling areas. All of the studies reported some level of contamination with at least one drug, and several reported contamination with all the drugs for which assays were performed. Such widespread contamination of work surfaces makes the potential for skin contact highly probable in the areas where these drugs are being handled. Evidence indicates that workers are being exposed to hazardous drugs and are experiencing serious health effects despite current work practice guidelines. Protection from hazardous drug exposures depends on safety programs established by employers.

\section{CONCLUSION}

In the research facilities there is a considerable misconception regarding the extent and risks of occupational exposure to hazardous chemicals and drugs. The most important reason for the lack of awareness of some very essential aspects of handling of biohazard drugs or chemicals is the absence of a formal institutional hazardous drug program. One such program must be launched in all institutes and all the researchers and technicians must be encouraged to learn as much as possible about the hazards and appropriate controls for the drugs they work with and to take appropriate action. Additionally, they should consult material data sheets (MSDSs), which chemical suppliers are required to provide. However, because pharmaceutical company MSDSs are often lacking in information and direction, additional sources of information should be sought and precautionary practices used to minimize exposures wherever possible. The survey results demonstrated that, the workers are truly not aware of all the potential exposure pathways and risks form hazardous drugs, even after the NIOS Alert.

It is also desirable to pursue risk and exposure evaluation, which must include estimates of safe exposure level, monitoring techniques, and exposure control methodologies to protect the workers and minimize environmental contamination. The information on safe levels, potential occupational health effects, monitoring techniques, and appropriate worker protection system must be available easily at all levels not only for the concerned staff, but also for the community as well.

\section{ACKNOWLEDGEMENT}

The completion of this study was made possible through the encouragement and assistance of Dr Mueen Ahmad KK, who has given his time and solicited advice to this study.

\section{CONFLICT OF INTEREST}

Author has no financial or personal relationship with other people or organizations that could inappropriately influence or bias the content of the paper.

\section{ABBREVIATIONS USED}

ASHP: (American Society of Hospital Pharmacists); BSC: (Biological Safety Cabinet); CDC: (centers for the disease control and prevention); MSDSs: (Material Safety Data Sheets); NIOSH: (National Institute of Occupational Safety and Health); OSHA: (Occupational Safety and Health Administration); PPE: (Personal Protective Equipment); SHPA: (Society of Hospital Pharmacist of Australia);

\section{ABOUT AUTHOR}

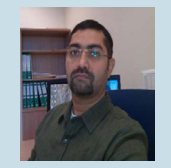

Dr Noor Kamil: Is a graduate of Faculty of Pharmacy, University of Karachi and he secured his PhD in Pharmacology form the same institute and University in Pakistan. Author has a keen interest in the neuropsychopharmacology of Antipsychotic drugs. Dr Kamil has a special interest in cancer prevalence, its treatment and toxicities associated with chemotherapy. He is particularly concerned in biohazards related to cytotoxic agents and published his work in the various scientific journals. 


\section{REFERENCES}

1. NIOSH. NIOSH Alert: preventing occupational exposures to antineoplastic and other hazardous drugs in health care settings. Cincinnati, OH: U.S. Department of Health and Human Services, Centers for Disease Control and Prevention, National Institute for Occupational Safety and Health, DHHS (NIOSH) Publication No. 2004-165.

2. NIOSH. NIOSH:Workplace Solutions: Personal Protective Equipment for Health Care Workers Who Work with Hazardous Drugs. Cincinnati, OH: U.S. Department of Health and Human Services, Centers for Disease Control and Prevention, National Institute for Occupational Safety and Health, DHHS (NIOSH) Publication No. 2009-106.

3. NIOSH. NIOSH list of antineoplastic and other hazardous drugs in healthcare settings. Cincinnati, OH: U.S. Department of Health and Human Services, Public Health Service, Centers for Disease Control and Prevention, National Institute for Occupational Safety and Health, DHHS (NIOSH) Publication No. 2012-150.

4. Krstev S, Perunicic B, Vidakovic A. Work practice and some adverse health effects in nurses handling antineoplastic drugs. Med Lav. 2003;94(5):432-9

5. Friese CR, Himes-Ferris L, Frasier MN, McCullagh MC, Griggs JJ. Structures and processes of care in ambulatory oncology settings and nurse-reported exposure to chemotherapy. BMJ QualSaf. 2012;21(9):753-9.

6. Lawson CC, Whelan EA, Hibert EN, Grajewski B, Spiegelman D and RichEdwards JW. Occupational factors and risk of preterm birth in nurses. Am J ObstetGynecol. 2009;200(1):51.e1-51.e8.

7. Lawson CC, Rocheleau CM, Whelan EA, LividotiHibert E, Grajewski B, Spiegelman D, and Rich-Edwards JW. Occupational exposures among nurses and risk of spontaneous abortion. Am J ObstetGynecol. 2012;206(4):327.e1-8

8. Gonzalez C. Occupational reproductive health and pregnancy hazards confronting health care workers. AAOHN J. 2011;59(9):373-6.

9. Blair A, Zheng T, Linos A, Stewart PA, Zhang YW and Cantor KP. Occupation and leukemia: A population-based case-control study in lowa and Minnesota. Am J Ind Med. 2001;40(1):3-14.

10. BLS. Occupational employment statistics homepage. May 2011 employment and wage estimates. Washington, DC: Bureau of Labor Statistics, [http://www. bls. gov/oes/home.htm]

11. ASHP (American Society of Health-System Pharmacists). ASHP guidelines on handling hazardous drugs. Am J Health-Syst Pharm. 2006;63:1172-93.

12. Baker E, and Connor T. Monitoring occupational exposures to cancer chemotherapy drugs. Am. J. Health Syst. Pharm. 1996;53(22):2713-23.

13. Sessink PJM, Rolf M-AE, Ryden NS. Evaluation of the PhaSeal hazardous drug containment system. Hosp Pharm. 1999;34(11):1311-17.

14. Pethran A, Schierl R, Hauff K, Grimm CH, Boos KS, Nowak D. Uptake of antineoplastic agents in pharmacy and hospital personnel. Part 1: monitoring of urinary concentrations. Int Arch Occup Environ Health. 2003;76(1):5-10.

15. Minoia C, Turci R, Sottani C, Schiavi A, Perbellini L, Angeleri S, Draicchio F Apostoli P. Application of high performance liquid chromatography/tandem mass spectrometry in the environmental and biological monitoring of healthcare personnel occupationally exposed to cyclophosphamide and ifosfamide. Rapid Commun Mass Spectrom. 1998;12(20):1485-93.

16. Wick C, Slawson MH, Jorgenson JA, Tyler LS. Using a closed-system protective device to reduce personnel exposure to antineoplastic agents. Am J Health Syst Pharm. 2003;60(22):2314-20

17. ASHP (American Society of Hospital Pharmacists). ASHP technical assistance bulletin on handling cytotoxic and hazardous drugs. Am J Hosp Pharm. 1990;47(5):1033-49.

18. OSHA. OSHA technical manual, 1999; TED 1-0.15A, Sec VI, Chapt II: Categorization of drugs as hazardous. [www.osha.gov/dts/osta/ otm/otm_vi/otm_vi_2. html\#2].

19. Occupational Safety and Health Administration (OSHA). Guidelines for Cytotoxic (Antineoplastic) Drugs, 1986; (Pub. No. 8-1.1). Washington, D.C.: Department of Labor, OSHA, Office of Occupational Medicine.

20. American Society of Health-System Pharmacists (ASHP). ASHP guidelines on handling hazardous drugs. Am J Health-Syst Pharm. 2006;63(1):1172-93.

21. Centers for the Disease Control and Prevention/National Institute of Health $(\mathrm{CDC} / \mathrm{NIH})$. Primary containment for biohazards: selection, installation and use of biological safety cabinets. 2nd ed. 2000; Washington, DC: U.S. Department of Health and Human Services, Public Health Service, Centers for Disease Control and Prevention and National Institutes of Health [www.cdc. gov/od/ohs/ biosfty/bsc/bsc.htm].

22. Mahon SM, Casperson DS, Yackzan S, Goodner S, Hasse B, Hawkins J, Parham J, Rimkus C, Schlomer M, Witcher V. Safe handling practices of cytotoxic drugs: the results of a chapter survey. OncolNurs Forum. 1994;21(7):1157-65.

23. Nieweg RMB, de Boer M, Dubbleman RC, Gall HE, Hesselman GM, Lenssen PCHP, van Maanen LWGM, Majoor PWFM, Ouwerkerk J, Slegt JH. Safe handling of antineoplastic drugs. Cancer Nurs. 1994;17(6):501-11.

24. Connor TH, Anderson RW, Sessink PJ, Broad-field L, Power LA. Surface contamination with antineoplastic agents in six cancer treatment centers in Canada and the United States. Am J Health Syst Pharm. 1999;56(14):1427-32.

25. FullerTP, Bain El, Sperrazza K, Mazzuckelli LF. A Survey of the Status of Hazardous Drug Awareness and Control in a Sample Massachusetts Nursing Population. Journal of Occupational and Environmental Hygiene. 2007;4(11):D113-D119.

26. Connor T, Sessink PB. Harrison, et al. Surface contamination of chemotherapy drug vials and evaluation of new vial-cleaning techniques: Results of three studies. Am. J. Health Syst. Pharm. 2005;62(5):475-84.

27. Mc Diarmid, M. Chemical hazards in health care high hazard, high risk, but low protection. Ann NY Acad Sci. 2006;1076(1):601-6.

28. John C. Symbol Making, Biohazard Symbol. History New York Times Magazine. 2001; November 18. http://www.oseh.umich.edu/pdf/HistoryofBiohazardSym bol.pdf

29. Black LA, Presson AC. Hazardous drugs. Occup Med: State of the Art Rev. 1997;12(4):669-85

30. Schreiber C, Radon K, Pethran A, Schierl R, Hauff K, Grimm C-H, Boos K-S, Nowak D. Uptake of antineoplastic agents in pharmacy personnel. Part 2: study of work-related risk factors. Int Arch Occup Environ Health. 2003;76(1):11-6.

31. Stuart $O A$, Stephens AD, Welch $L$, Sugerbaker PH. Safety monitoring of the coliseum technique for heated intraoperative intraperitoneal chemotherapy with mitomycin C. Ann SurgOncol. 2002;9(2):186-91.

32. Kiffmeyer TK, Kube C, Opiolka S, Schmidt KG, Schöppe G, Sessink PJM. Vapor pressures, evaporation behaviour and airborne concentrations of hazardous drugs: implications for occupational safety. Pharmeaceut J. 2002;268:331-7.

33. Larson RR, Khazaeli MB, Dillon HK. A new monitoring method using solid sorbent media for evaluation of airborne cyclophosphamide and other antineoplastic agents. ApplOccup Environ Hyg. 2003;18(2):120-31.

34. McDevitt JJ, Lees PSJ, McDiarmid MA. Exposure of hospital pharmacists and nurses to antineoplastic agents. J Occup Med.1993;35(1):57-60.

35. Rubino FM, Floridia L, Pietropaolo AM, Tavazzani M, Colombi A. Measurement of surface contamination by certain antineoplastic drugs using high-performance liquid chromatography: applications in occupational hygiene investigations in hospital environments. Med Lav. 1999;90(4):572-83.

36. Vandenbroucke J, Robays $H$. How to protect environment and employees against cytotoxic agents, the UZ Ghent experience. J Oncol Pharm Practice. $2001 ; 6(4): 146-52$

37. Connor TH, Anderson RW, Sessink PJ, Spivey SM. Effectiveness of a closed-system device in containing surface contamination with cyclophos phamide and ifosfamide in an i.v. admixture area. Am J Health Syst Pharm. 2002;59(1):68-72

38. Wick C, Slawson MH, Jorgenson JA, Tyler LS Using a closed-system protective device to reduce personnel exposure to antineoplastic agents. Am J Health Syst Pharm. 2003;60(22):2314-2320.

39. Sargent EV, Kirk GD. Establishing airborne exposure control limits in the pharmaceutical industry. Am IndHygAssoc J. 1988; 49(6):309-13. 